\title{
High Molecular Weight Hyaluronic Acid (Hyalubrix/HyalOne) for Treating Symptomatic Hip Osteoarthritis
}

\section{Alberto Migliore ${ }^{*}$, Gianfranco Gigliucci ${ }^{1}$, Sandro Tormenta ${ }^{2}$, Angelo De Cata ${ }^{3}$, Luca Gallelli ${ }^{4}$, Giovanni lolascon}

'Rheumatology Unit and Research Center, S. Pietro Fatebenefratelli Hospital, Rome, Italy

${ }^{2}$ Radiology Unit, S. Pietro Fatebenefratelli Hospital, Rome, Italy

${ }^{3}$ Department of Medical Sciences, Division of Internal Medicine and Rheumatology Unit, IRCCS Casa Sollievo della Sofferenza Hospital, San Giovanni Rotondo (FG), Italy ${ }^{4}$ Chair of Pharmacology Department of Health Science, University of Catanzaro School of Medicine, and Operative Unit of Clinical Pharmacology and Pharmacovigilance, Azienda Ospedaliera MaterDomini, Catanzaro, Italy

${ }^{5}$ Department of Medical and Surgical Specialties and Dentistry, University of Campania "Luigi Vanvitelli", Naples, Italy

Article Info

\section{Article Notes}

Received: April 17, 2019

Accepted: May 28, 2019

\section{${ }^{*}$ Correspondence:}

Dr. Alberto Migliore, Rheumatology Unit and Research

Center, S. Pietro Fatebenefratelli Hospital, Rome, Italy; Email: alberto.migliore.12@outlook.it.

(C) 2019 Migliore A. This article is distributed under the terms of the Creative Commons Attribution 4.0 International License.

\section{Keywords}

Hyaluronic acid

Hip osteoarthritis

Total hip replacement

Viscosupplementation

Hyalubrix

Joint arthropathies

\section{ABSTRACT}

Hip osteoarthritis (OA) causes a set of symptoms that may lead to severe patient impairment, social isolation and morbidity, especially in the elderly. Eventually, patients become candidates for total hip replacement (THR); yet surgery may cause morbidity, increase costs and too risky in some cases. Viscosupplementation (VS) by intra-articular hyaluronic acid (HA) injection has been shown to be effective to treat symptoms consequent to knee OA. VS is a viable option to treat hip OA too, provided that appropriate techniques are used to inject HA into the articular space. To this end, ultrasound-guided approaches have been developed that allow appropriate intra-articular injection eliminating the risk of exposure to ionizing radiation entailed by fluoroscopy. This review summarizes the results of clinical investigations concerning the use of a high molecular weight HA formulation, Hyalubrix/HyalOne, for treating hip OA symptoms. These results show that Hyalubrix/HyalOne has an enhanced safety profile, is effective from the first injection, significantly reduces NSAIDs consumption, and can be used for repeated therapy cycles over more years as a conservative therapy to delay THR. Nevertheless, it must be also considered that a significant placebo effect linked to intra-articular injections may exist, thus reducing the magnitude of HA benefits.

\section{Hip Osteoarthritis}

Osteoarthritis $(\mathrm{OA})$ is the most common cause of joint pain in adults, particularly among the elderly. Hip OA pain may interfere with a patient's ability to perform routine daily activities: As the hip is a weight-bearing joint, problems caused by hip OA are usually disabling and lead to social isolation; further, hip OA is a frequent cause of morbidity. Prevalence of hip OA is about $17 \%$ in white males and $9 \%$ in white women over 60 years of age ${ }^{1}$. Treatment aims to relieve pain and to preserve or restore joint mobility ${ }^{2}$, it may be either non-pharmacological or pharmacological, and may involve surgery ${ }^{1,3,4}$. Pharmacological treatment includes acetaminophen as a first option, followed by NSAIDs, at the lowest effective dose, to be used in patients who respond inadequately. Patients showing a gastrointestinal risk profile may be treated with non-selective NSAIDs associated with a gastroprotective agent, or a selective COX-2 inhibitor. Finally, patients in whom NSAIDs, including COX2 selective inhibitors, are ineffective and/or poorly tolerated or contraindicated, may be treated with opioid analgesics, with or without acetaminophen ${ }^{3}$. Any hip OA pharmacological treatment must be protracted over time, possibly forever, raising concerns about short- and long-term side effects of medications, as well as 
involving a continuous economic burden, either for the patient or the national health systems. Surgery is regarded as the last option when other approaches have failed; nonetheless, total hip replacement (THR) is becoming more common in Western countries ${ }^{5,6}$. THR has a $90 \%$ success rate, yet it is associated with morbidity including infection, blood clots, loosening, dislocation, nerve and blood vessel injury ${ }^{7}$. Furthermore, the mortality rate consequent to THR ranges from $0.13-0.33 \%$ in the United States ${ }^{8-10}$ to $2.2 \%$ in Italy ${ }^{11,12}$. Accordingly, treatment of symptomatic OA should aim to delay surgery while guaranteeing the patient an acceptable quality of life.

\section{Viscosupplementation using Hyaluronic Acid (HA)}

Recent guidelines concerning non-pharmacological interventions for $\mathrm{OA}$, based on results achieved in treatment of knee $\mathrm{OA}$, indicate that hyaluronic acid viscosupplementation is appropriate for treating hip $\mathrm{OA}$ patients not responding to conventional analgesic or pharmacological treatment alternatives ${ }^{3,13,14}$.

Hyaluronic acid, also referred to as hyaluronan or sodium hyaluronate, is the most abundant glycosaminoglycan in mammalian tissue. HA consists of long chains (up to $30 \mu \mathrm{m}$ ) of repeating disaccharide units of $\mathrm{N}$-acetylglucosamine and glucuronic acid. The largest quantity is found in the synovial fluid (SF) of the diarthrodial joints, with concentrations ranging between 0.5 and $4 \mathrm{mg} / \mathrm{mL}$; here, molecular weight (MW) of HA chains ranges from 2 to $10 \mathrm{MDa}^{15,16}$. Under dynamic loading, non-ionic weak forces between HA molecules confer to HA unique non-Newtonian rheological properties, including shear thinning and reduction of viscosity ${ }^{17-19}$; this confers SF outstanding visco-elasticity, shock-absorbing and lubricating properties, particularly during high shear or compression conditions ${ }^{20}$. Joint arthropathies, including $\mathrm{OA}$, are associated with a reduction of the molecular weight and concentration of hyaluronan in the synovial fluid, as inflammatory cytokines adversely affect the metabolism of HA-producing fibroblasts, leading to the synthesis of HA with a smaller molecular weight ${ }^{21}$. HA MW reduction, coupled with its dilution because of increased synovial membrane permeability, causes SF rheological properties to worsen, further contributing to OA progression ${ }^{16}$.

Based on these observations, HA viscosupplementation by intra-articular injection was introduced as an $\mathrm{OA}$ therapeutic approach. Viscosupplementation involves the supplementation or replacement of the SF with exogenous HA with a higher MW than that of endogenous HA or subjected to cross-linking to enhance its rheological properties. This strategy can be adopted to restore or at least improve SF viscoelasticity, decrease symptoms, and improve joint functionality ${ }^{22}$. Since then, HA has been intensively used as a viscosupplementing agent mainly to treat symptoms of knee $\mathrm{OA}^{23}$. The higher $\mathrm{MW}$ as well as any crosslinking increase HA degradation time, favoring its persistence in the $\mathrm{SF}^{24-27}$. Accordingly, different HA formulations used for intra-articular injection to treat OA may display significantly different characteristics and effects, and their safety and performance should be assessed on a case-by-case basis through long-term, comparative studies.

\section{Hyalubrix /HyalOne: A High MW HA Viscosupplementing Formulation}

One high MW HA formulation, Hylubrix/HyalOne (Fidia Farmaceutici S.p.A., Abano Terme, Padova, Italy) has been extensively used as a viscosupplementing agent for intraarticular injection in different forms of joint OA. Hyalubrix is a $1.5 \%(15 \mathrm{mg} / \mathrm{ml})$ solution of non-modified HA obtained by biofermentation, possessing a molecular weight within the 1.5-2.0 MDa range ${ }^{24}$. Hyalubrix ( $2 \mathrm{ml} / 30 \mathrm{mg}$ ) and HyalOne $4 \mathrm{ml}$ / $60 \mathrm{mg}$ ) are both available on the market as three injections and one single injection regimen respectively. HA formulations with this MW show rheological properties resembling those of native HA in the SF, as their crossover point $(\sim 0.8 \mathrm{~Hz})$ is significantly closer to that observed in joint fluid samples $(\sim 0.4 \mathrm{~Hz})$ compared to lower MW formulations $(\sim 11 \mathrm{~Hz})$ also used for intra-articular therapy ${ }^{28}$. High MW HA, having longer molecular chains, may display more interactions with natural phospholipids, contributing to increased lubricating power ${ }^{29}$ and may be more effective in preventing fluid drainage from the joint, thanks to its greater outflow buffering effect ${ }^{30}$. Finally, the clearance time of HA in the 1.5-2.0 MDa range was found to be significantly longer $(120 \mathrm{hrs})$ than that of HA having a $<1$ MDa MW (60 hrs) when injected in rabbit knee joints $^{31}$. Hyalubrix/HyalOne, therefore, was considered an optimal viscosupplementing agent candidate.

Indeed, its intra-articular administration to treat $\mathrm{OA}$ symptoms was tested in several controlled and observational clinical trials. A multicenter, large-scale, observational study by Schieb ${ }^{32}$ involved 1523 patients. In this study, $81.3 \%$ of subjects suffered from knee OA, while the others were affected by traumatic arthropathies. Patients received three weekly Hyalubrix intra-articular injections and were observed for a maximum of six weeks. Intensity of pain and mobility were evaluated according to a Visual Analogue Scale (VAS), both at the start and end of treatment. Patients experienced a significant pain reduction; upon conclusion of administration of Hyalubrix, $91.2 \%$ of patients reported significantly less pain and $85.3 \%$ reported significantly better, or completely recovered mobility than before beginning treatment. In 2011 Foti and colleagues ${ }^{33}$ carried out another large-scale (47 centers, 1266 patients, 1707 OA joints), prospective observational study, involving intraarticular injection of Hyalubrix in different $\mathrm{OA}$ affected synovial joints (knee: $82.0 \%$ of total joints being treated; hip: 9.0\%; shoulder: 6.3\%; tibio-tarsal joint: $1.5 \%$; and 
trapeziometacarpal joint: 1.2\%). Participants received intra-articular HA (30 mg/2 ml) in one or more joints, as required, once a week for three consecutive weeks. The participants were then assessed two weeks after the final injection to evaluate the variation in efficacy parameters compared to the baseline visit. Mean VAS for joint pain in motion significantly decreased over the study period for all joints, and a similar (but smaller) change occurred in VAS for pain at rest. Further, a significant improvement in motor function was observed, as indicated by the Stanford Health Assessment Questionnaire scores. The number of patients using NSAIDs decreased over the study period (only $4 \%$ of subjects were using them at the follow-up visit). Three weekly injections, even if at different doses, were also found to be effective in alleviating pain in two investigations concerning intra-articular injection of $7.5 \mathrm{mg} / 0.5 \mathrm{ml}$ or 15 mg /1 ml Hyalubrix $30 \mathrm{mg}$ in OA trapeziocarpal joints ${ }^{34,35}$. Patients $(\mathrm{N}=16,32$ joints) in the study by Ingegnoli experienced a significant decrease in VAS pain after only 2 weeks of treatment and this result was maintained at week 24; those treated by Di Sante $(\mathrm{N}=31,31$ joints) experienced a statistically significant VAS score reduction at 1 and 3 months, but not at the 6-month follow-up. One $30 \mathrm{mg} / 2 \mathrm{ml}$ Hyalubrix intra-articular injection per week for three weeks was also found to be effective in reducing subjective pain and WOMAC scores of patients $(\mathrm{N}=14,14$ joints) suffering knee OA; objective optoelectronic digital analysis of gait confirmed a significant improvement of a set of biomechanical parameters ${ }^{36}$. Filardo and colleagues ${ }^{37}$ compared the injection of Platelet Rich Plasma (PRP) to that of Hyalubrix $30 \mathrm{mg}$ for treating symptoms of knee OA. The investigators found at all follow-up visits $(2,6$, and 12 months after treatment) that three weekly HA injections (2 $\mathrm{ml} / 30 \mathrm{mg}$ each, $\mathrm{N}=89$ patients and joints) were as effective as three weekly $5 \mathrm{ml}$ PRP injections ( $\mathrm{N}=94$ patients and joints) where the International Knee Documentation Committee (IKDC) subjective score, the Knee Injury and Osteoarthritis Outcome Score, their quality of life (EuroQol score), the Tegner score, the transpatellar circumference, and the joint range of motion were concerned.

Priano and Guelfi ${ }^{38}$ investigated how post-meniscectomy Hyalubrix $30 \mathrm{mg}$ injection affected the post-surgical course of patients, finding that patients treated with HA $(\mathrm{N}=51)$ experienced significantly less pain while walking, at rest, during activity, and at pressure, and had better joint mobility and functional evaluation according to the Lysholm score than patients undergoing no HA injections $(\mathrm{N}=49)$.

The cited studies showed that Hyalubrix/HyalOne had quite a good safety and tolerability profile; adverse events, mostly transient and having minor clinical significance, were those usually observed with HA formulations ${ }^{39}$ such as reddening, itching, or pain at the injection site. Incidence of adverse events in the Schieb ${ }^{32}$ and Foti ${ }^{33}$ large trials varied between $0.5 \%$ and of $0.8 \%$ (Table 1 ).

\section{Intra-articular Hyalubrix/HyalOne Injection to Treat Hip OA Symptoms}

Viscosupplementation of the hip for treating $\mathrm{OA}$ symptoms has lagged behind HA injection of the knee,

Table 1: List of the most relevant clinical studies using Hyalubrix for viscosupplementation of other joints.

\begin{tabular}{|c|c|c|c|c|c|c|c|}
\hline First author (year) & Study type & Product & Dose & $\mathrm{N}^{\circ}$ patients & Follow-up & Primary endpoint & Main finding(s) \\
\hline Smiderle $2007^{36}$ & Observational & Hyalubrix & 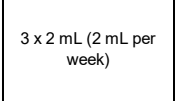 & 14 & 6 weeks & $\begin{array}{c}\text { Pain assessed by the } \\
\text { numerical rating scale (NRS) } \\
\text { and WOMAC osteoarthritis } \\
\text { index }\end{array}$ & $\begin{array}{l}\text { Gait analysis of treated patients with grade II or grade III osteoarthritis } \\
\text { revealed significant improvement of most cinematics and kinetics } \\
\text { parameters. Amelioration of symptoms (pain and WOMAC index). }\end{array}$ \\
\hline Foti $2011^{33}$ & Observational & Hyalubrix & $\begin{array}{c}3 \times 2 \mathrm{~mL}(2 \mathrm{~mL} \text { per } \\
\text { week) }\end{array}$ & 1266 & 5 weeks & $\begin{array}{l}\text { Safety (number of adverse } \\
\text { events) and details of } \\
\text { usage of the IA sodium } \\
\text { hyaluronate syringe device }\end{array}$ & $\begin{array}{l}\text { The adverse event (AE) rate was } 0.8 \%(95 \% \mathrm{Cl}, 0.4 \text { to } 1.5) \text {. No } \\
\text { serious adverse events occurred. Coadministration of local } \\
\text { anesthetic was required by up to } 10 \% \text { of patients. Statistically } \\
\text { significant improvements in VAS, HAQ, and EuroQoL were recorded } \\
\text { in multiple joints }\end{array}$ \\
\hline Ingegnoli $2011^{34}$ & Observational & Hyalubrix & $\begin{array}{c}3 \times 0,5 \mathrm{~mL}(0,5 \mathrm{~mL} \text { per } \\
\text { week) }\end{array}$ & 16 & 24 weeks & $\begin{array}{c}\text { Treatment impact assessed } \\
\text { by VAS pain measurement }\end{array}$ & $\begin{array}{l}\text { Significant clinical improvement was obtained by the decrease in } \\
\text { visual analog scale for pain after } 2 \text { weeks of treatment and this result } \\
\text { is maintained at week } 24 \text {. The Dreiser's index also decreased after } \\
\text { week } 2 \text { and remained stable after } 6 \text { months. Power Doppler signal } \\
\text { significantly decreased after } 2 \text { weeks of treatment, even if this result } \\
\text { was not maintained at week } 24 \text {. No significant decrease in the } \\
\text { synovial hypertrophy score was observed during the study. }\end{array}$ \\
\hline Di Sante $2011^{35}$ & Case series & Hyalubrix & $\begin{array}{c}3 \times 1 \mathrm{~mL}(1 \mathrm{~mL} \text { per } \\
\text { week) }\end{array}$ & 31 & 6 months & $\begin{array}{c}\text { Evaluation of the mean VAS } \\
\text { score for pain and of the mean } \\
\text { Duruöz Hand Index (DHI) for } \\
\text { hand functionality }\end{array}$ & $\begin{array}{l}\text { Statistically significant VAS score reduction was observed at } 1 \text { and } 3 \\
\text { months after the end of treatment but not at 6-month follow-up. No } \\
\text { statistically significant difference was found on the DHI total score at } \\
1 \text { and 6-month follow-ups. }\end{array}$ \\
\hline Filardo $2015^{37}$ & Randomized controlled & Hyalubrix & $\begin{array}{c}3 \times \underset{2}{2 \mathrm{~mL}(2 \mathrm{~mL} \text { per }} \\
\text { week) }\end{array}$ & 192 & 12 months & $\begin{array}{c}\text { International Knee } \\
\text { Documentation Committee } \\
\text { (IKDC) subjective score } \\
\text { improvement at the 12-month } \\
\text { follow-up }\end{array}$ & $\begin{array}{l}\text { PRP injections were found to cause more post-injection swelling and } \\
\text { pain compared to HA injections. Both treatments were effective in } \\
\text { improving knee functionality and in reducing symptoms. Since PRP } \\
\text { does not provide clear clinical advantages with respect to HA, it } \\
\text { should not be preferred to viscosupplementation to treat patients } \\
\text { affected by knee cartilage degeneration and osteoarthritis. }\end{array}$ \\
\hline
\end{tabular}


possibly because of the anatomic differences between the two joints that make injection in the hip more difficult and present more risk of harming delicate structures such as vessels and nerves. Hip injection by the handsfree technique is prone to errors, leading to not injecting HA into the articular space ${ }^{40}$; alternatively, fluoroscopy is expensive, time-consuming, and exposes the patient and the physicians to unwanted radiation, and its use should be limited to few applications ${ }^{41}$. To overcome these limitations, our group opted for performing HA injections under ultrasound (US) guidance ${ }^{42}$, according to an anterosuperior approach that has been perfected and standardized over time ${ }^{43-46}$. In short, the approach involves using an US transducer together with a sterile bioptic target device while patients are placed supine with the hip at $15-20^{\circ}$ internal rotation: the hip joint is scanned according to an anterior parasagittal approach, lateral to the femoral vessels. The transducer is aligned with the long axis of the femoral neck, comprising the acetabulum and the femoral head. The injection is performed by inserting a 20 -gauge $(9 \mathrm{~cm})$ spinal needle into the biopsy guide: using biopsy real-time guidance software, the needle is advanced into the anterior capsular recess, at the level of the femoral head and, when in contact with it, is retracted by $1 \mathrm{~mm}$ before starting the injection. Verification of injection into the articular space is allowed by real-time monitoring (direct visualization of viscous fluid or air bubbles) and power Doppler imaging (flow signals in intra-articular recess). The color Doppler vision also allows the physician to avoid blood vessels. An open study on a large register ${ }^{47}$ of 1906 patients (4002 injections) undergoing HA injection according to this approach confirmed this technique is well tolerated with few, and exclusively local, side effects. The technique was shown to facilitate achieving an accurate delivery of the injected product as well as the repeatability of the injections, allowing long-term management of hip $\mathrm{OA}^{42,44,47}$. Indeed, the low incidence of adverse events $(<5 \%)$ observed ${ }^{47}$ was similar to the safety results obtained by Tikiz and colleagues ${ }^{48}$ by fluoroscopic guidance, indicating US guidance achieves successful IA injection of the medication.

\section{Results by Our Group}

Preliminary results concerning Hyalubrix/HyalOne USguided intra-articular injection for treating Hip OA were provided in 2008 at the OARSI (OsteoArthritis Research Society International) World Congress on Osteoarthritis ${ }^{49}$, describing how 239 adults (271 joints), ambulatory patients suffering from hip OA grade 1 to 3 according to Kellgren and Lawrence, were prospectively recruited and injected using (4 ml / $60 \mathrm{mg}$ ) of HyalOne every six months or, if needed because of their clinical conditions, every three months. Patients were then followed-up every three months up to 18 months after the first injection.
Treatment was shown to be effective, since both the Lequesne index and the VAS pain score were observed to be significantly reduced at all time points versus baseline for all assessment criteria. NSAIDs consumption was also found to be significantly lower at all time points versus that recorded during the month preceding the first injection. No local or systemic adverse events were reported. Such observations suggested continuous intra-articular use of Hyalubrix/HyalOne in hip OA patients was effective, even on a long-term basis, to maintain the positive effects obtained after the first injection, allowing the reduction of NSAID consumption. These findings were confirmed by a prospective cohort study including Kellgren-Lawrence (KL) grade I, II, III, or IV symptomatic hip OA patients aged $\geq 40$ years and experiencing pain for at least one year ${ }^{50}$. The study involved 120 patients that were subjected to $4 \mathrm{ml} / 60 \mathrm{mg}$ intra-articular HyalOne injections every six months and, if needed, to additional injections every three months, and were followed up to 18 months after the first injection. Scores collected were the same used during the previous study ${ }^{49}$; a statistically significant reduction in algofunctional indexes was observed even at 3 months after the first injection. At 12 months, $80 \%$ of the patients achieved $\mathrm{a} \geq 30 \%$ decrease in symptoms. These results were maintained over time through cyclical ultrasound guided injections, with one administered at least every 6 months. Adverse events were mild, transient, and observed in about $3 \%$ of injections.

Therapeutic effectiveness in hip OA symptoms treatment by intra-articular injections of Hyalone was also confirmed by a double-blind, controlled trial aimed to investigate their effect versus that of local analgesia induced by injecting mepivacaine ${ }^{51}$. Hip OA patients were included if aged $>40$ years and suffering from VAS pain $\geq 4$ persisting for at least one month before the first injection. Patients were randomized to be treated either by two $60 \mathrm{mg} / 4 \mathrm{ml}$ Hyalone or $20 \mathrm{mg} / 1 \mathrm{ml}$ mepivacaine hydrochloride USguided intra-articular injections carried out one month apart. The primary objective of the study was to compare the Lequesne algofunctional index of the two groups at 6 months (26 weeks) after the first injection. Secondary objectives included comparing the two groups for pain intensity, NSAIDs consumption, and overall subjective and objective global assessment. Forty-two patients were recruited, $85.7 \%$ of whom were affected by KL Grade III OA. Concerning the Lequesne's Index, both treatment groups significantly improved at 3 and 6 months versus baseline. The HA was significantly superior to mepivacaine at both time points; pain also significantly improved versus baseline and was significantly less in the HA group at both follow-up visits. Patients in both groups showed decreased NSAIDs consumption, and in both groups subjective and objective global assessment scores were significantly better at both follow-up visits than at baseline for both 
groups. Concerning these parameters, the two groups did not display statistically significant differences. One HA patient experienced intra-articular pain after injection that resolved after 7 days with acetaminophen $2 \mathrm{~g} /$ day. One mepivacaine patient suffered from mildly intense pain at the injection site that resolved spontaneously after 36 hours. Results from the prospective study previously mentioned $^{49}$ concerning a cohort of hip OA patients treated by HyalOne injections showed that the number of subjects who, at the end of the 18-month follow-up period, had to undergo THR was low (8 patients out of 239, for a THR rate of about 3\%). Consistent with indications of the EULAR agenda ${ }^{3}$ prompting researchers to assess whether viscosupplementation can slow the progression of osteoarthritis and/or to delay joint replacement, a further study was therefore carried out to compare the recommendations for THR at baseline, provided by a group of independent orthopedists, with the actual rate of THR received by the patients during a cohort 48-month follow$u^{52}$. Six orthopedists each independently assessed whether 176 patients suffering from hip OA, treated with US-guided intra-articular injections $(60 \mathrm{mg} / 4 \mathrm{ml}$ every six months, with additional injections every three months if needed) of HyalOne were candidates for THR according to their baseline age, body mass index, pain VAS, Lequesne index, global patient assessment, global physician assessment, nonsteroidal anti-inflammatory drug intake, and hip X-ray. At 24 months, 159 out of 176 (90\%) patients did not undergo THR. At 48 months, $82 \%(\mathrm{~N}=144)$ of patients had avoided THR. At 24 months, only 17 out of the 93 patients considered candidates for THR (that is, in which 4, 5, or 6 orthopedic surgeons agreed that the patient was a suitable candidate for THR) had undergone THR corresponding to a $82 \%$ survival rate. At 48 months, this rate had decreased to $66 \%$. Patients for whom respectively $3,2,1$ or no surgeons agreed that the patient was a candidate for THR did not undergo arthroplasty. Thus, HyalOne US-guided intraarticular injection was shown to delay THR in the context of actual management of symptomatic hip OA patients, indicating viscosupplementation using HyalOne may be effectively carried out to delay proposing a patient for THR.

Given these results, a long-term follow-up study ${ }^{53}$ was recently carried out to report the efficacy of US-guided (60 $\mathrm{mg} / 4 \mathrm{ml}$ ) HyalOne injection in a large population of hip OA patients, repeated at least 2 times per year up to seven years. Data were collected from the ANTIAGE registry ${ }^{47}$. Values of Lequesne index, pain VAS, NSAIDs intake, global medical and patient assessments were evaluated every three months from the baseline to the end of the follow-up, seven years later. Radiographic evaluation was carried out every 24 months through standard X-ray. The inclusion criteria were: age $\geq 18$ years, symptomatic hip osteoarthritis for one year, and follow-up $\geq 84$ months. The 1022 included patients were categorized by age, class, gender, and body mass index (BMI). All groups showed a statistically significant reduction at all time points, compared to baseline, of all scores under assessment, with slight differences in the subgroups of overweight, obese, and over 70-year-old patients. Pain improvement was greater $(46.7 \%)$ in patients younger than 40 , and lower, but still clinically significant $(25 \%)$ in patients older than 70 , with other age classes scoring intermediate values. Older patients ( $>80$ years) experienced about a $45 \%$ improvement in their functional scores at the last followup visit, with other ages experiencing a similar rate (from $34 \%$ to $50 \%$ ). In any case, all patients, whatever their age or BMI, experienced a significant improvement for all scores under assessment at six months after treatment and, most significantly, repeating HA injections allowed the maintenance of such improvements for the following six years and a half. Over seven years, no systemic or severe local side effects were ever reported. Some patients experienced pain after injection that lasted from several hours to few days, confirming previous data ${ }^{49,50,52}$. In conclusion, the study showed that HyalOne, while displaying an excellent safety profile, did not lose efficacy over time even after repeated injections over more years.

\section{Additional Studies from Other Groups Working with Hyalubrix/HyalOne on Hip OA}

Other investigations from independent researchers support the conclusion that Hyalubrix/HyalOne intraarticular injection is a consistent approach to treat hip OA symptoms, allowing repeated injections over time and postponing replacement surgery. Results from the study already cited by Foti et al. ${ }^{33}$ who treated successfully 1707 OA joints, included 154 hips. Paoloni et al. ${ }^{54}$ performed a prospective, open study in 20 hip OA patients to assess the clinical effects of 3 weekly US-guided intra-articular injections of $30 \mathrm{mg} / 2 \mathrm{ml}$ Hyalubrix on pain and function at 1, 3, and 6-month follow-ups through VAS and WOMAC scores, as well as changes in the kinematics and kinetics of gait at the 6-month follow-up, using a gait analysis system based on recordings collected using infrared video cameras $^{55-57}$. At all time points, pain, as well as stiffness and disability, significantly decreased versus baseline. Three months after injections patients walked with higher cadence and stride length and had a significant increase in the pelvic tilt at heel contact and in hip flexion-extension moment at loading response sub-phases of gait cycle. De Lucia et al. ${ }^{58}$ carried out an observational study involving 95 hips of 91 patients, 80 affected by primary OA, 15 suffering from OA secondary to inflammatory rheumatic diseases. Patients were randomly assigned to receive a USguided intra-articular injection using a medium-MW HA derivative (Hylan G-F 20; Synvisc; Genzyme, 56 hips) or Hyalubrix/HyalOne (39 hips). Injections were carried out at recruitment, at 1 and 2 months, and then every 6 months 
thereafter. Patients were assessed at inclusion, and then after $1,6,12$, and 24 months after the last injection. A significant decrease of VAS and WOMAC total scores was observed after only 1 month. Such improvement was maintained over 2 years independently from the radiological degree of $\mathrm{OA}$, with both HA derivatives; yet improvement was faster in the group treated with Hyalubrix. Mauro et al..$^{59}$ enrolled 40 patients affected by hip OA who were subjected to three US-guided injections of Hyalubrix 45 days apart, combined with three physical therapy sessions a week, including proprioceptive rehabilitation of the lower limbs, gait training, balance training, for up to a total of 30 sessions (10 weeks), starting from one week after the first injection. Examinations were carried out after each intra-articular injection and 45 and 60 days after the last injection. Pain perceived by patients during activity dropped significantly already after the first injection. This result was maintained at all following visits. Significant improvements were also observed in the evaluation in hip disability, OA-related pain at rest, daily functioning and NSAIDs intake, confirming the effectiveness of combined Hyalubrix injection and physical therapy Table 2).

\section{Discussion}

Taken together, the results of the studies summarized in the previous paragraphs show that intra-articular injection of Hyalubrix/HyalOne to treat pain symptoms and disability consequent to hip $\mathrm{OA}$ is beneficial, starting from the very first injection, and allows for repeated therapy cycles, at time intervals of months, and over more years, to maintain the beneficial effects over time.

The maintenance of Hyalubrix/HyalOne effects over the time occurring between two consecutive injections still calls for a definitive explanation: while HA having the MW of Hyalubrix/HyalOne has a residence time significantly longer than the one exhibited by HA of lower MW, complete

Table 2: List of the most relevant clinical studies using Hyalubrix and other HA-based treatments for hip viscosupplementation.

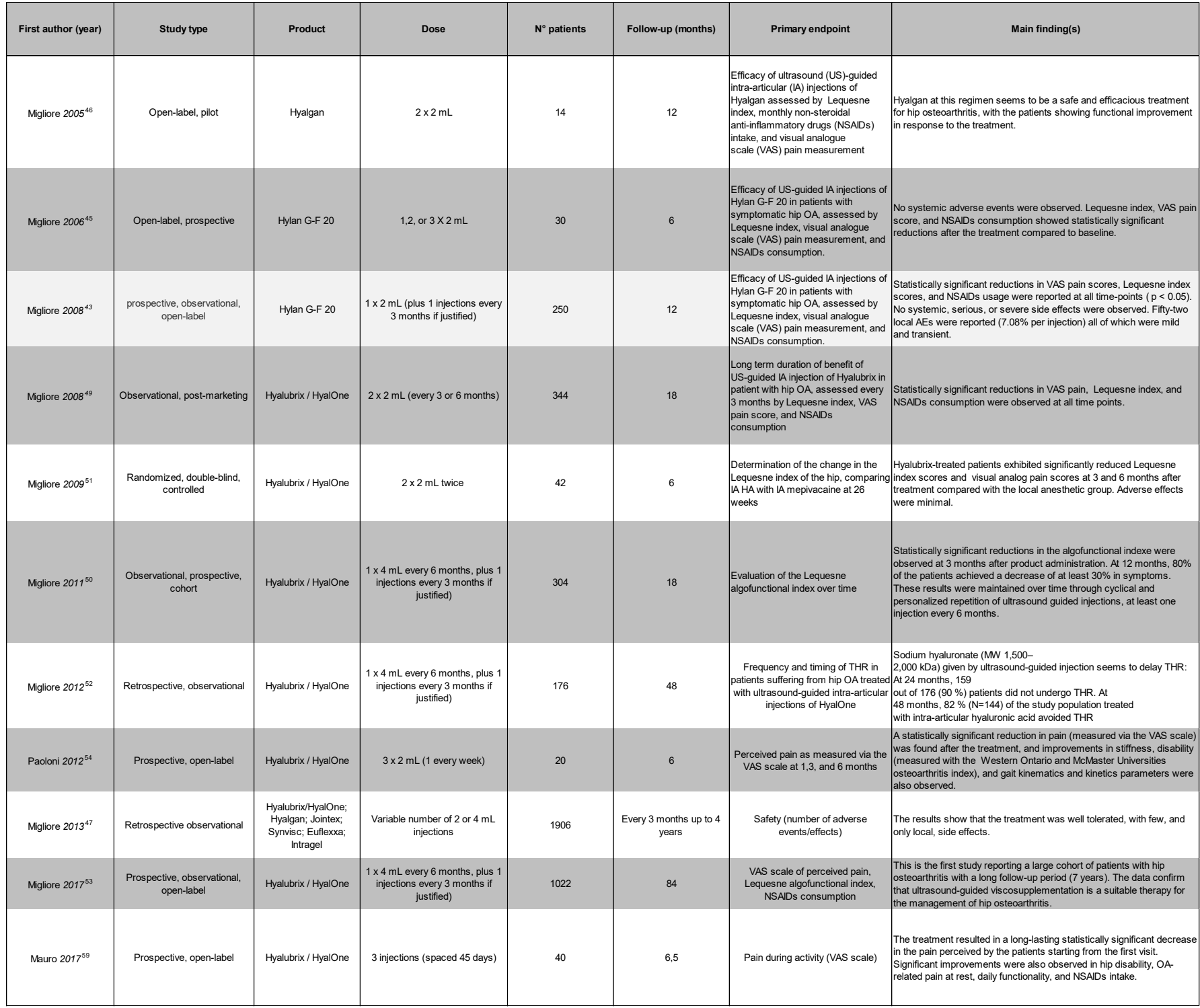


clearance is still expected within a few days ${ }^{31}$. It is possible that high MW HA, in addition to temporarily restoring SF lubrication and viscoelasticity, may act as a mechanical filter towards inflammatory mediators, reducing their sensitizing effect on nociceptors ${ }^{60}$.

Results of the above-mentioned studies also show that hip OA patients who benefit from the effect of intraarticular injection of Hyalubrix/HyalOne significantly reduce their NSAID consumption. This, in turn, may also reduce the costs associated with disease management and with the side-effects induced by NSAIDs. Better mobility may lead to improvements in patients' daily activities, such as work (with productive gain) and self-care (with reduced assistance-related costs). Finally, results of the present study indicate that hip viscosupplementation with Hyalubrix/ HyalOne may be effective in delaying THR in hip OA patients and may be considered a conservative treatment to be carried out concomitantly with other non-pharmacological approaches ${ }^{14,61}$ before resorting to arthroplasty, as suggested by the OARSI recommendations ${ }^{62,63}$. Such a conservative treatment, as shown in the latter study by our group ${ }^{53}$ may be protracted for years without losing its benefit or causing significant incremental side effects.

Of note, it was suggested that a significant placebo effect intrinsic to knee intra-articular injections may exist $^{64,66,67,68}$, and that the effect size of HA might have been overestimated because of the influence of non-blinded or improperly blinded trials ${ }^{65}$. In light of this, the possibility that such a placebo effect accounts, at least partially, for the benefits of intra-articular Hyalubrix/HyalOne injections observed in patients with hip osteoarthritis cannot be excluded, and further blinded studies should be carried out to better estimate the HA effect size.

\section{Conclusions}

In conclusion, these data support the use of Hyalubrix/HyalOne as a safe and effective background therapy in hip OA. Management of hip OA should involve viscosupplementation, together with other interventions, and orthopedists who do not routinely perform hip injections should be aware of the degree of efficacy which may be achieved by hip viscosupplementation.

\section{References}

1. Zhang YQ, Jordan JM. Epidemiology of osteoarthritis. Clin Geriatr Med. 2010; 26: 355-369.

2. Roman-Blas JA, Bizzi E, Largo R, et al. An update on the up and coming therapies to treat osteoarthritis, a multifaceted disease. Expert Opin Pharmacother. 2016; 4: 1-12.

3. Zhang W, Doherty M, Arden N, et al EULAR Standing Committee for International Clinical Studies Including Therapeutics (ESCISIT) EULAR evidence based recommendations for the management of hip osteoarthritis: report of a task force of the EULAR Standing Committee for International Clinical Studies Including Therapeutics (ESCISIT). Ann Rheum Dis. 2005 May; 64(5): 669-81. Epub 2004 Oct 7.
4. Hochberg MC, Altman RD, April KT, et al. American College of Rheumatology. American College of Rheumatology 2012 recommendations for the use of nonpharmacologic and pharmacologic therapies in osteoarthritis of the hand, hip, and knee. Arthritis Care Res (Hoboken). 2012 Apr; 64(4): 465-74.

5. Nemes S, Gordon M, Rogmark C, et al. Projections of total hip replacement in Sweden from 2013 to 2030. Acta Orthop. 2014 Jun; 85(3): 238-43.

6. Kurtz SM, Ong KL, Lau E, et al. Impact of the economic downturn on total joint replacement demand in the United States: updated projections to 2021. J Bone Joint Surg Am. 2014 Apr 16; 96(8): 62430.

7. Phillips CB, Barrett JA, Losina E, Mahomed NN, et al. Incidence rates of dislocation, pulmonary embolism, and deep infection during the first six months after elective total hip replacement. J Bone Joint Surg Am. 2003 Jan; 85-A(1): 20-6.

8. Goldberg VM, Kettelkamp DB, Colyer RA. Osteoarthritis of the knee. In: Moskowitz RW, Howell DS, Goldberg VM, HJMankin HJ (eds). Osteoarthritis: diagnosis and medical/surgical management. Philadelphia: WB Saunders. 1992; 599-620.

9. Zhan C, Kaczmarek R, Loyo-Berrios N, et al. Incidence and short-term outcomes of primary and revision hip replacement in the United States. J Bone Joint Surg Am. 2007 Mar; 89(3): 526-33.

10. Illingworth KD, El Bitar YF, Banerjee D, et al. Inpatient mortality after primary total hip arthroplasty: analysis from the National Inpatient Sample database. J Arthroplasty. 2015 Mar; 30(3): 369-73.

11. Sperati A, Picconi O, Tancioni V, et al. Outcomes of hip replacement: hospital-based longitudinal study in Lazio region (Italy). Ann Ig. 2008 Mar-Apr; 20(2): 141-57.

12. Bagge E, Bjelle A, Valkenburg HA, et al. Prevalence of radiographic osteoarthritis in two elderly European populations. Rheumatol Int. $1992 ; 12(1): 33-8$

13. Rivera F. Can viscosupplementation be used in the hip? An Italian perspective. Orthopedics. 2014 Jan; 37(1): 48-55.

14. Migliore A, Bizzi E, Herrero-Beaumont J, et al. The discrepancy between recommendations and clinical practice for viscosupplementation in osteoarthritis: mind the gap! Eur Rev Med Pharmacol Sci. 2015 Apr; 19(7): 1124-9.

15. Fraser JR, Laurent TC, Laurent UB. Hyaluronan: its nature, distribution, functions and turnover. J Intern Med. 1997 Jul; 242(1): 27-33.

16. Band PA, Heeter J, Wisniewski HG, et al. Hyaluronan molecular weight distribution is associated with the risk of knee osteoarthritis progression. Osteoarthritis Cartilage. 2015 Jan; 23(1): 70-6.

17. Balazs EA, Watson D, Duff IF, et al. Hyaluronic acid in synovial fluid. I. Molecular parameters of hyaluronic acid in normal and arthritis human fluids. Arthritis Rheum. 1967 Aug; 10(4): 357-76.

18. Bothner H, Wik O. Rheology of hyaluronate. Acta Otolaryngol Suppl. 1987; 442: 25-30.

19. Balazs EA, Denlinger JL. Sodium hyaluronate and joint function. Equine Vet Sci. 1985; 5: 217-228.

20. Cullis-Hill D, Ghosh P. The role of hyaluronic acid in joint stability--a hypothesis for hip dysplasia and allied disorders. Med Hypotheses. 1987 Jun; 23(2): 171-85.

21. Dahl LB, Dahl IM, Engström-Laurent A, et al. Concentration and molecular weight of sodium hyaluronate in synovial fluid from patients with rheumatoid arthritis and other arthropathies. Ann Rheum Dis. 1985 Dec; 44(12): 817-22

22. Balazs EA, Denlinger JL. Viscosupplementation: a new concept in the treatment of osteoarthritis. J Rheumatol Suppl. 1993 Aug; 39: 3-9. 
23. Campbell KA, Erickson BJ, Saltzman BM, et al. Is Local Viscosupplementation Injection Clinically Superior to Other Therapies in the Treatment of Osteoarthritis of the Knee: A Systematic Review of Overlapping Meta-analyses. Arthroscopy. 2015 Oct; 31(10): 2036-45. e14.

24. Guidolin D, Franceschi F. Viscosupplementation with high molecular weight native hyaluronan. Focus on a $1500-2000 \mathrm{KDa}$ fraction (Hyalubrix®). Eur Rev Med Pharmacol Sci. 2014; 18(21): 3326-38.

25. Ghosh P, Guidolin D. Potential mechanism of action of intra-articular hyaluronan therapy in osteoarthritis: are the effects molecular weight dependent? Semin Arthritis Rheum. 2002 Aug; 32(1): 10-37.

26. Collins MN, Birkinshaw C. Physical properties of crosslinked hyaluronic acid hydrogels. J Mater Sci Mater Med. 2008 Nov; 19(11): 3335-43.

27. Highley CB, Prestwich GD, Burdick JA. Recent advances in hyaluronic acid hydrogels for biomedical applications. Curr Opin Biotechnol. 2016 Aug; 40: 35-40.

28. Mazzucco D, McKinley G, Scott RD, et al. Rheology of joint fluid in tota knee arthroplasty patients. J Orthop Res. 2002 Nov; 20(6): 1157-63.

29. Pasquali-Ronchetti I, Quaglino D, Mori G, et al. Hyaluronanphospholipid interactions. J Struct Biol. 1997 Oct; 120(1): 1-10.

30. Coleman PJ, Scott D, Mason RM, et al. Role of hyaluronan chain length in buffering interstitial flow across synovium in rabbits. J Physiol 2000 Jul 15; 526 Pt 2: 425-34.

31. Komatsu S, Iwata H, Nabeshima T. Studies on the kinetics, metabolism and re-utilization after intra-articular administration of hyaluronan to rabbits. Arzneim Forsch. 1999; 49: 427-433.

32. Schieb F. Intraartikulär injizierte Hyaluronsäure bei arthropathien. Arthritis Rheum. 2003; 6: 338-340.

33. Foti $\mathrm{C}$, Cisari $\mathrm{C}$, Carda $\mathrm{S}$, et al. A prospective observational study of the clinical efficacy and safety of intra-articular sodium hyaluronate in synovial joints with osteoarthritis. Eur J Phys Rehabil Med. 2011 Sep; 47(3): 407-15.

34. Ingegnoli F, Soldi A, Meroni PL. Power Doppler sonography and clinical monitoring for hyaluronic Acid treatment of rhizarthrosis: a pilot study. J Hand Microsurg. 2011 Dec; 3(2): 51-4.

35. Di Sante L, Cacchio A, Scettri P, et al. Ultrasound-guided procedure for the treatment of trapeziometacarpal osteoarthritis. Clin Rheumatol. 2011 Sep; 30(9): 1195-200.

36. Smiderle C, Scapin M, Baldo M, et al. Gait analysis of changes in clinica and biomechanical parameters in osteoarthritis knee patients after intraarticular infiltrationwith high molecular weight hyaluronan. Eur Med Phys. 2007; 43: 1-3.

37. Filardo G, Di Matteo B, Di Martino A, et al. Platelet-Rich Plasma Intra-articular Knee Injections Show No Superiority Versus Viscosupplementation: A Randomized Controlled Trial. Am J Sports Med. 2015 Jul; 43(7): 1575-82.

38. Priano F, Guelfi M. Efficacy of intra-articular hyaluronic acid (Hyalubrix ${ }^{\circledR}$ ) in arthroscopy. Artroscopia. 2007; 8: 1-12.

39. Hamburger MI, Lakhanpal S, Mooar PA, et al. Intra-articular hyaluronans: a review of product-specific safety profiles. Semin Arthritis Rheum. 2003 Apr; 32(5): 296-309

40. Leopold SS, Battista V, Oliverio JA. Safety and efficacy of intraarticular hip injection using anatomic landmarks. Clin Orthop Relat Res. 2001 Oct; (391): 192-7.

41. Diraçoğlu D, Alptekin K, Dikici F, et al. Evaluation of needle positioning during blind intra-articular hip injections for osteoarthritis: fluoroscopy versus arthrography. Arch Phys Med Rehabil. 2009 Dec 90(12): 2112-5. doi: 10.1016/j.apmr.2009.08.137.
42. Qvistgaard E, Kristoffersen H, Terslev L, et al. Guidance by ultrasound of intra-articular injections in the knee and hip joints. Osteoarthritis Cartilage. 2001 Aug; 9(6): 512-7.

43. Migliore A, Tormenta S, Massafra U, et al. Intra-articular administration of hylan G-F 20 in patients with symptomatic hip osteoarthritis: tolerability and effectiveness in a large cohort study in clinical practice. Curr Med Res Opin. 2008a May; 24(5): 1309-16.

44. Migliore A, Martin LS, Alimonti A, et al. Efficacy and safety of viscosupplementation by ultrasound-guided intra-articular injection in osteoarthritis of the hip. Osteoarthritis Cartilage. 2003 Apr; 11(4): 305-6.

45. Migliore A, Tormenta S, Martin Martin LS, et al. The symptomatic effects of intra-articular administration of hylan G-F 20 on osteoarthritis of the hip: clinical data of 6 months follow-up. Clin Rheumatol. 2006 May; 25(3): 389-93.

46. Migliore A, Tormenta S, Massafra U, et al. Repeated ultrasoundguided intra-articular injections of $40 \mathrm{mg}$ of Hyalgan may be useful in symptomatic relief of hip osteoarthritis. Osteoarthritis Cartilage. 2005 Dec; 13(12): 1126-7.

47. Migliore A, Tormenta S, Laganà B, et al. Safety of intra-articular hip injection of hyaluronic acid products by ultrasound guidance: an open study from ANTIAGE register. Eur Rev Med Pharmacol Sci. 2013 Jul; 17(13): 1752-9

48. Tikiz C, Unlü Z, Sener A, et al. Comparison of the efficacy of lower and higher molecular weight viscosupplementation in the treatment of hip osteoarthritis. Clin Rheumatol. 2005 Jun; 24(3): 244-50.

49. Migliore A, Bizzi E, Massafra U, et al. 18 months followup after intra-articular administration of Hyalubrix ${ }^{\circledR}$ in 344 patients with symptomatic osteoarthritis of the hip. Osteoarthritis and Cartilage. 2008b; 16 (S4): S118-S119.

50. Migliore A, Massafra U, Bizzi E, et al. Intra-articular injection of hyaluronic acid (MW 1,500-2,000 kDa; HyalOne) in symptomatic osteoarthritis of the hip: a prospective cohort study. Arch Orthop Trauma Surg. 2011 Dec; 131(12): 1677-85.

51. Migliore A, Massafra U, Bizzi E, et al. Comparative, double-blind, controlled study of intra-articular hyaluronic acid (Hyalubrix) injections versus local anesthetic in osteoarthritis of the hip. Arthritis Res Ther. 2009; 11(6): R183

52. Migliore A, Bella A, Bisignani M, et al. Total hip replacement rate in a cohort of patients affected by symptomatic hip osteoarthritis following intra-articular sodium hyaluronate (MW 1,500-2,000 kDa) ORTOBRIX study. Clin Rheumatol. 2012 Aug; 31(8): 1187-96.

53. Migliore A, Massafra U, Frediani B, et al. HyalOne $\AA$ in the treatment of symptomatic hip OA - data from the ANTIAGE register: seven years of observation. Eur Rev Med Pharmacol Sci. 2017 Apr; 21(7): 16351644

54. Paoloni M, Di Sante L, Dimaggio M, et al. Kinematic and kinetic modifications in walking pattern of hip osteoarthritis patients induced by intra-articular injections of hyaluronic acid. Clin Biomech (Bristol, Avon). 2012 Aug; 27(7): 661-5.

55. Laroche D, PozzoT, Ornetti P, etal. Effects of loss of metatarsophalangea joint mobility on gait in rheumatoid arthritis patients. Rheumatology (Oxford). 2006 Apr; 45(4): 435-40. Epub 2005 Oct 25.

56. Ornetti P, Maillefert JF, Laroche D, et al. Gait analysis as a quantifiable outcome measure in hip or knee osteoarthritis: a systematic review. Joint Bone Spine. 2010 0ct; 77(5): 421-5.

57. Meyer CA, Corten K, Fieuws S, et al. Biomechanical gait features associated with hip osteoarthritis: Towards a better definition of clinical hallmarks. J Orthop Res. 2015 Oct; 33(10): 1498-507.

58. De Lucia O, Comi D, Valcamonica E, et al AB0998 Medium and high molecular weight hyaluronic acid injected in hip joint by US-guided 
technique in patients with primary or secondary hip osteoarthritis: A 2 year observational study. Annals of the Rheumatic Diseases. 2013; 71: 695 .

59. Mauro GL, Sanfilippo A, Scaturro D. The effectiveness of intraarticular injections of Hyalubrix $®$ combined with exercise therapy in the treatment of hip osteoarthritis. Clin Cases Miner Bone Metab. 2017 May-Aug; 14(2): 146-152.

60. Pozo MA, Balazs EA, Belmonte C. Reduction of sensory responses to passive movements of inflamed knee joints by hylan, a hyaluronan derivative. Exp Brain Res. 1997 Aug; 116(1): 3-9.

61. Fernandes L, Hagen KB, Bijlsma JW, et al. European League Against Rheumatism (EULAR). EULAR recommendations for the nonpharmacological core management of hip and knee osteoarthritis. Ann Rheum Dis. 2013 Jul; 72(7): 1125-35.

62. Chevalier X, Henrotin Y. Osteoarthritis Committee of the French Society for Rheumatology. OARSI recommendations on knee and hip osteoarthritis: use with discernment. Joint Bone Spine. 2009 Oct; 76(5): 455-7.

63. Zhang W, Nuki G, Moskowitz RW, et al. OARSI recommendations for the management of hip and knee osteoarthritis: part III: Changes in evidence following systematic cumulative update of research published through January 2009. Osteoarthritis Cartilage. 2010 Apr; 18(4): 476-99.
64. Altman RD, Devji $\mathrm{T}$, Bhandari $\mathrm{M}$, et al. Clinical benefit of intraarticular saline as a comparator in clinical trials of knee osteoarthritis treatments: A systematic review and meta-analysis of randomized trials. Semin Arthritis Rheum. 2016 Oct; 46(2): 151-159. doi: 10.1016/j.semarthrit.2016.04.003. Epub 2016 Apr 27.

65. Jevsevar D, Donnelly P, Brown GA, et al. Viscosupplementation for Osteoarthritis of the Knee: A Systematic Review of the Evidence. J Bone Joint Surg Am. 2015 Dec 16; 97(24): 2047-60. doi: 10.2106/ JBJS.N.00743.

66. Bannuru RR, Schmid CH, Kent DM, et al. Comparative effectiveness of pharmacologic interventions for knee osteoarthritis: a systematic review and network meta-analysis. Ann Intern Med. 2015 Jan 6; 162(1): 46-54. doi: 10.7326/M14-1231.

67. Pai SK, Allgar V, Giannoudis PV. Are intra-articular injections of Hylan G-F 20 efficacious in painful osteoarthritis of the knee? A systematic review \& meta-analysis. Int J Clin Pract. 2014 Aug; 68(8): 1041-7. doi: 10.1111/ijcp.12430. Epub 2014 May 5.

68. Saltzman BM, Leroux T, Meyer MA, et al.The Therapeutic Effect of Intra-articular Normal Saline Injections for Knee Osteoarthritis: A Meta-analysis of Evidence Level 1 Studies. Am J Sports Med. 2017 Sep; 45(11): 2647-2653. doi: 10.1177/0363546516680607. Epub 2016 Dec 27. 